\title{
Mahalanobis-Taguchi System-based criteria selection for strategy formulation: a case in a training institution
}

\author{
Seyed Ali Hadighi ${ }^{1,2}$, Navid Sahebjamnia $^{3}$, Iraj Mahdavi ${ }^{2^{*}}$, Hadi Asadollahpour ${ }^{2}$ and Hosna Shafieian ${ }^{2}$
}

\begin{abstract}
The increasing complexity of decision making in a severely dynamic competitive environment of the universe has urged the wise managers to have relevant strategic plans for their firms. Strategy is not formulated from one criterion but from multiple criteria in environmental scanning, and often, considering all of them is not possible. A list of criteria utilizing Delphi was selected by consultation with company experts. By reviewing the literature and strategy experts' proposals, the list is then classified into five categories, namely, human resource, equipment, market, supply chain, and rules. Since all the criteria may not be necessary for the decision process, as they are eliminated in the early stage traditionally, it is important to identify the prime set of criteria, which is a subset of the original criteria and affects decision making. Utilizing these criteria, a Mahalanobis-Taguchi System-based tool was developed to facilitate the selection of a prime set of criteria, which is a subset of the original criteria for ensuring that only ineffective subcriteria are eliminated and the conditions are prepared for relevant strategy formulation. Mahalanobis distance was used for making a measurement scale to distinguish ineffective subcriteria from significant criteria in the environmental scanning stage. The principles of the Taguchi method were used for screening the important criteria in the system and generate the prime set of criteria for each category. One can use these criteria within each category instead of all criteria for the identification of a suitable institution in training. To validate the proposed approach, a case study has been conducted for 38 educational institutions in Iran. The results demonstrated the usefulness of the proposed approach.
\end{abstract}

Keywords: Mahalanobis distance; Measurement scale; Service institution; Strategy formulation

\section{Introduction}

Strategy formulation is sometimes referred to as determining where you are now, where you plan to go, and finally how to get there. It consists of performing a situation analysis, self-evaluation, and competitor analysis in both inside and outside of the organization while setting the objectives concurrent with the assessment. Strategy formulation is the process of developing long-term goals for an effective management of environmental factors. Strategy formulation consists of two basic components: one is situation analysis which is the process of finding a strategic fit between external opportunities and internal strengths while working around external threats

\footnotetext{
* Correspondence: irajarash@rediffmail.com

${ }^{2}$ Department of Industrial Engineering, Mazandaran University of Science and Technology, Babol, Iran

Full list of author information is available at the end of the article
}

and internal weaknesses, and the other component is developing strategies based on goals. Many approaches and techniques can be used to analyze strategic cases in the process of strategic management (Dincer 2004).

Among several existing approaches, strengths, weaknesses, opportunities, and threats (SWOT) analysis, evaluating each of the indicated terms in an organization, is the most acclaimed (Hill and Westbrook 1997). SWOT analysis is the most significant part of strategic formulation. By identifying the strengths, weaknesses, opportunities, and threats, the organization can build strategies upon its strengths, eliminate its weaknesses, and exploit its opportunities or utilize them to encounter the threats. The strengths and weaknesses are considered as an internal organization environment appraisal, while the opportunities and threats are considered as an external organization environment appraisal (Dyson 2004). 
Hadighi et al. (2013) proposed a framework based on clustering algorithm for strategic formulation of corporate organization. They formed departmental clusters according to correlation among factors and goals in each department. Then, strategies are presented based on the generated organizational clusters. Goals, factors, and strategies are known as the three main elements in strategy formulation. The interrelationship among them should be considered as an integrated set, while in common methods, these relationships are vague. In another research, Hadighi et al. (2012) presented a strategy formulation framework for developing strategies on more accurate and objective bases by considering all the components. They identify whether the organization is intrinsically a production or a service company. Then, the environmental factors are explored including opportunities and threats, in the light of organization's strengths and weaknesses. At this stage, the factor-goal matrix is formed by considering the impact of factors on every individual goal. Finally, the goals with higher similarities are embedded within the same cluster, and strategies were generated for each of them.

Many approaches and techniques were developed for strategic management, such as the traditional SWOT analysis (Bellman and Zadeh 1970), analytical SWOT method (Chen et al. 1992), resource-based view (Paiva et al. 2008; Gordon et al. 2005), and quantitative SWOT methods (Chen and Hsieh 2000; David 2001). Fuzzy quantified SWOT (Kuo-liang and Shu-chen 2008), decision tree (Bunn and Thomas 1977), and quality function deployment (Killen et al. 2005) are used to support decision making in a competitive environment in a given organization.

In this paper, a new method of environmental factors' filtering has been developed. To this end, a list of criteria utilizing Delphi was selected by consultation with company experts. By reviewing the literature and strategy experts' proposals, the list is then classified into five categories, namely, human resource, equipment, market, supply chain, and rules. Since all the criteria may not be necessary for the decision process, as they are eliminated in the early stage traditionally, it is important to identify the prime set of criteria, which is a subset of the original criteria and affects decision making. Utilizing these criteria, a Mahalanobis-Taguchi System (MTS)-based tool was developed to facilitate the selection of a prime set of criteria, which is a subset of the original criteria for ensuring that only ineffective subcriteria are eliminated and the conditions are prepared for relevant strategy formulation. Mahalanobis distance (MD) was used for making a measurement scale to distinguish ineffective subcriteria from significant criteria in the environmental scanning stage. In this manner, the main contributions of this paper can be highlighted as follows:
- Consideration of all environmental factors

- Consideration of the interaction among factors

- Application of a MTS method for environmental scanning

- Utilization of a quantitative method for detecting abnormal factors

Organizations are considered to be of two general types: (1) service organization and (2) production organization. For each organization, according to its characteristics and nature of the problems of concern, the key indicators based on priorities would be significant.

\section{Data gathering}

Gathering data on factors was practiced at first in production companies. In emerging service companies, the significance of data gathering has spread to this ever increasing sector of the industry. So, data gathering is just as applicable to services as it is to production in general. Only live experiments with real customers and real transactions can provide the type of data needed for truly innovative services. However, live tests are difficult to control and risky to both customer relations and firm creditability, and therefore, most services are designed by brainstorming or trial and error, with limited success. Eventually, services are labor intensive, while manufacturing is more capital intensive (Russell and Taylor 2006).

The most important factors and subfactors as experts specified are shown in Table 1 and Figure 1. Since in most cases of SWOT analysis considering all factors is almost impossible, in general, a limited set of factors is being considered and some factors are eliminated according to an overall view of strategy makers. Since all the criteria may not be necessary for the decision process, it is important to identify the prime set of criteria, which is a subset of the original criteria. In order to identify the prime criteria, experimental design becomes complex and difficult to manage. In this study, an alternative new approach is identified to the experimental design, the MTS-based decision tool. The purpose is MTS-based criteria selection for suitable criteria for strategy formulation. In this paper, we are going to define a normal group which is called Mahalanobis space by utilizing MD. Mahalanobis space (MS) is a database for the normal group involving mean vector, standard deviation vector, and inverse of the correlation vector (Taguchi and Jugulum 2000). This space provides a reference point for the measurement scale. According to MTS theory, the average value of MDs is 1 for all the observations in MS (Taguchi et al. 2005).

\section{Materials and methods}

In this section the samples taken, decision criteria and the acceptable rating, normal and abnormal observations, and also MTS framework will be discussed. 
Table 1 The steps to design and optimize the MTS

\begin{tabular}{|c|c|c|c|c|}
\hline Subcriteria (before MTS) & Range of variations & Suitability ratings & Notation for implementation & Subcriteria (after MTS) \\
\hline Human resource & & & (h) & \\
\hline Appearance & $0-100$ & $\geq 70$ & $h_{1}$ & - \\
\hline Specialty & $0-100$ & $\geq 85$ & $h_{2}$ & - \\
\hline Courtesy & $0-100$ & $\geq 75$ & $h_{3}$ & - \\
\hline Experience & $0-100$ & $\geq 70$ & $h_{4}$ & Experience \\
\hline Attitude & $0-100$ & $\geq 75$ & $h_{5}$ & Attitude \\
\hline Public relation & $0-100$ & $\geq 80$ & $h_{6}$ & Public relation \\
\hline Motivation & $0-100$ & $\geq 80$ & $h_{7}$ & Motivation \\
\hline Education & $0-100$ & $\geq 85$ & $h_{8}$ & Education \\
\hline Performance & $0-100$ & $\geq 80$ & $h_{9}$ & Performance \\
\hline Timeliness & $0-100$ & $\geq 90$ & $h_{10}$ & Timeliness \\
\hline Equipment & & & (q) & \\
\hline Functionality & $0-4$ & $\geq 3$ & $q_{1}$ & Functionality \\
\hline Aesthetic & $0-4$ & $\geq 2$ & $q_{2}$ & - \\
\hline Comfort ability & $0-4$ & $\geq 3$ & $q_{3}$ & Comfort ability \\
\hline Multifunction & 0,1 (no, yes) & 1 & $q_{4}$ & - \\
\hline Market & & & $(m)$ & \\
\hline Demand & 0\%-100\% & $\geq 70 \%$ & $m_{1}$ & Demand \\
\hline Organization brand & $1,2,3(A, B, C)$ & $\geq B$ & $m_{2}$ & Organization brand \\
\hline Competitors & $-5,+5$ & $2-5$ & $m_{3}$ & Competitors \\
\hline Economic parameters & $-5,+5$ & $0-5$ & $m_{4}$ & Economic parameters \\
\hline Customer attitude & $-5,+5$ & $1-5$ & $m_{5}$ & Customer attitude \\
\hline Supply chain & & & (c) & \\
\hline Reputation & $1,2,3(A, B, C)$ & $\geq B$ & $c_{1}$ & Reputation \\
\hline Financial ability & 0,1 & 1 & $c_{2}$ & Financial ability \\
\hline Support services & $0-9$ & $\geq 6$ & $c_{3}$ & Support services \\
\hline Timeliness & $0-9$ & $\geq 7$ & $C_{4}$ & Timeliness \\
\hline Rules & & & $(r)$ & \\
\hline Social rules & $-2,+2$ & $0-2$ & $r_{1}$ & - \\
\hline Tax & $-3,+3$ & $1-3$ & $r_{2}$ & - \\
\hline Discipline & $-3,+3$ & $1-3$ & $r_{3}$ & Discipline \\
\hline Organizational rules & $-5,+5$ & $\geq 3$ & $r_{4}$ & - \\
\hline
\end{tabular}

\section{Samples}

The samples are taken from 38 educational institutions all acting in the capital city of Tehran, Iran. The selected institutions are those which have been approved by the quality assurance department for utilization. Their main activity is in training and holding lectures for requesters.

\section{Decision criteria and its appropriate ratings}

The key factors and subfactors to be considered for selecting the suitable educational institutions according to experts' replies are the human resource factor with ten subfactors $\left(h_{1}, \ldots, h_{10}\right)$, namely, appearance, specialty, courtesy, experience, attitude, public relation, motivation, education, performance, and timeliness. These attributes are purely qualitative, and their ranges of variations have been considered from 0 for the least to 100 for the maximum effect. Equipment has four subfactors $\left(q_{1}, \ldots, q_{4}\right)$ such as functionality, aesthetic, comfort ability, with the range from 0 to 4 for the worst to the best condition, and multifunction (with the answer yes and no or 1 and 0 , respectively). The factor market consists of five subfactors $\left(m_{1}, \ldots, m_{5}\right)$ such as demand which is defined as the average percentage of having educated customers during the year (\%); organization brand which is defined as $A, B$, or $C$, from the best to the worst $(1,2$, or 3 , respectively); competitors from -5 to the most +5 ; 


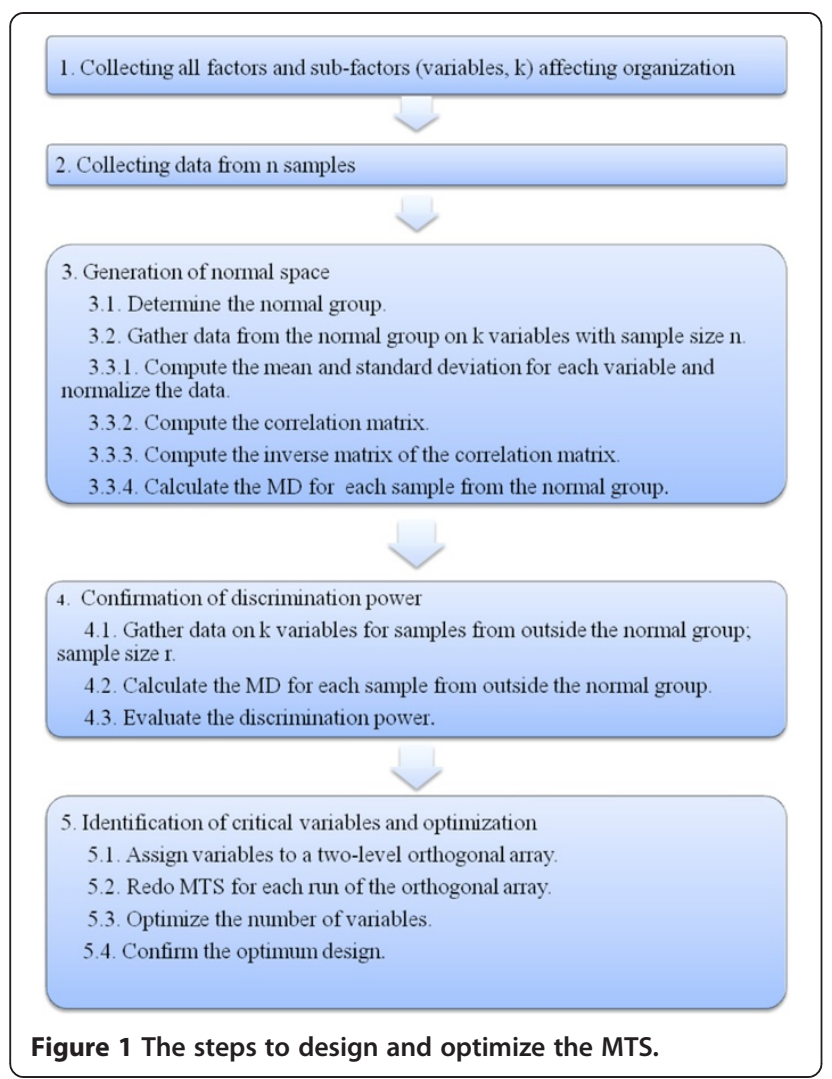

economic parameters also expressed as -5 to the most +5 ; and finally, customer attitude from -5 to +5 , too. The factor supply chain $\left(c_{1}, \ldots, c_{4}\right)$ also includes reputation defined as $A, B$, or $C$, from the most famous to the least (or 1,2, or 3, respectively); financial ability expressed as the average current ratio per month, less than 1 and equal or greater than 1 ( 0 and 1 , respectively); support service from 0 for the least to 9 for the greatest; and timeliness also from 0 for the minimum to 9 for the maximum. Finally, the factor rules $\left(r_{1}, \ldots, r_{4}\right)$ includes social rules from the rules by worst effect -2 to the best effect +2 , tax with the worst effect -3 to the best effect +3 , discipline also from -3 to +3 , and organizational rules stated as -5 to +5 from worst to the best, respectively. The whole factors and subfactors with their range of variability, limits of acceptability, and notations for implementation before and after MTS are shown in Table 1.

\section{Normal and abnormal observations}

The data used in this study were collected from 38 educational institutions including normal and abnormal observations. The normal group which is called Mahalanobis space was formed based on observations on 29 sample institutions, those which do not have any value out of the acceptable limit. The abnormal group was built according to nine institutions, which have one or more criteria values beyond the acceptable range.

\section{Mahalanobis-Taguchi System}

The selection of a prime set of subcriteria for an individual main criterion was calculated iteratively utilizing the following steps (Taguchi and Jugulum 2000, 2002; Taguchi et al. 2001). The algorithm of processing the article is shown in Table 1.

\section{Making a measurement scale with MS as the reference scale}

The first step for the construction of measurement scale was the collection of normal observations and then the normalization of these observations by using mean and standard deviation obtained from the normal observations. MDs corresponding to all these observations were computed using the inverse of the correlation matrix method (Taguchi et al. 2001).

$$
\begin{aligned}
\mathrm{MD}_{i} & =D_{i}{ }^{2}=\frac{1}{k} Z_{i j}^{T} A^{-1} Z_{i j} \\
& =\frac{1}{k}\left(z_{i 1}, z_{i 2}, \ldots, z_{i k}\right) A^{-1}\left(\begin{array}{c}
z_{i 1} \\
\vdots \\
z_{i k}
\end{array}\right),
\end{aligned}
$$

where $Z_{i}$ is the normalized vector obtained by normalizing the values of $X_{j}(j=1,2,3 \ldots, k)$

$$
\begin{gathered}
z_{i j}=\frac{X_{i j}-\bar{X}_{j}}{S_{j}}, \\
\bar{X}_{j}=\frac{\sum_{i=1}^{n} X_{i j}}{n_{i}},
\end{gathered}
$$

where $X_{i j}$ is the value of $j$ th subcriteria in $i$ th observation

$$
S_{j}=\sqrt{\frac{\sum_{i=1}^{n}\left(X_{i j}-\bar{X}_{j}^{2}\right)}{n-1}},
$$

where $S_{j}$ is the standard deviation of $j$ th subcriteria, $k$ is the number of subcriteria, $n$ is the number of observations, $T$ is the transpose of the normalized vector, and $A^{-1}$ is the inverse of the correlation matrix.

It can be considered that MD in Equation 1 was obtained by scaling (that is by dividing with $k$ ) the original MD. Since MDs were used to define the normal group, we called this group as Mahalanobis space. Mahalanobis space is a database for the normal group involving mean vector, standard deviation vector, and inverse of the correlation vector (Taguchi and Jugulum 2000). This space provides a reference point for the measurement scale. According to MTS theory, the average value of MDs is 1 for all the observations in MS (Taguchi et al. 2001). 
Table $2 L_{32}\left(2^{27}\right)$ OA and average response for the larger-the-better $\mathrm{S} / \mathrm{N}$ ratio

\begin{tabular}{|c|c|c|c|c|c|c|c|c|c|c|c|c|c|c|c|c|c|c|c|c|c|c|c|c|c|c|c|c|c|c|c|}
\hline Run & $h_{1}$ & $h_{2}$ & $h_{3}$ & $h_{4}$ & $h_{5}$ & $h_{6}$ & $h_{7}$ & $h_{8}$ & $h_{9}$ & $h_{10}$ & $q_{1}$ & $q_{2}$ & $q_{3}$ & $q_{4}$ & $m_{1}$ & $m_{2}$ & $m_{3}$ & $m_{4}$ & $m_{5}$ & $c_{1}$ & $c_{2}$ & $c_{3}$ & $c_{4}$ & $r_{1}$ & $r_{2}$ & $r_{3}$ & $r_{4}$ & 28 & 29 & 30 & \\
\hline & 1 & 1 & 1 & 1 & 1 & 1 & 1 & 1 & 1 & 1 & 1 & 1 & 1 & 1 & 1 & 1 & 1 & 1 & 1 & 1 & 1 & 1 & 1 & 1 & 1 & 1 & 1 & 1 & 1 & 1 & \\
\hline 2 & 1 & 1 & 1 & 1 & 1 & 1 & 1 & 1 & 1 & 1 & 1 & 1 & 1 & 1 & 1 & 2 & 2 & 2 & 2 & 2 & 2 & 2 & 2 & 2 & 2 & 2 & 2 & 2 & 2 & 2 & \\
\hline & 1 & 1 & 1 & 1 & 1 & 1 & 1 & 2 & 2 & 2 & 2 & 2 & 2 & 2 & 2 & 1 & 1 & 1 & 1 & 1 & 1 & 1 & 1 & 2 & 2 & 2 & 2 & 2 & 2 & & \\
\hline 4 & 1 & 1 & 1 & 1 & 1 & 1 & 1 & 2 & 2 & 2 & 2 & 2 & 2 & 2 & 2 & 2 & 2 & 2 & 2 & 2 & 2 & 2 & 2 & 1 & 1 & 1 & 1 & 1 & 1 & 1 & \\
\hline & 1 & 1 & 1 & 2 & 2 & 2 & 2 & 1 & 1 & 1 & 1 & 2 & 2 & 2 & 2 & 1 & 1 & 1 & 1 & 2 & 2 & 2 & 2 & 1 & 1 & 1 & 1 & 2 & 2 & 2 & \\
\hline 6 & 1 & 1 & 1 & 2 & 2 & 2 & 2 & 1 & 1 & 1 & 1 & 2 & 2 & 2 & 2 & 2 & 2 & 2 & 2 & 1 & 1 & 1 & 1 & 2 & 2 & 2 & 2 & 1 & 1 & 1 & \\
\hline & 1 & 1 & 1 & 2 & 2 & 2 & 2 & 2 & 2 & 2 & 2 & 1 & 1 & 1 & 1 & 1 & 1 & 1 & 1 & 2 & 2 & 2 & 2 & 2 & 2 & 2 & 2 & 1 & 1 & 1 & \\
\hline & 1 & 1 & 1 & 2 & 2 & 2 & 2 & 2 & 2 & 2 & 2 & 1 & 1 & 1 & 1 & 2 & 2 & 2 & 2 & 1 & 1 & 1 & 1 & 1 & 1 & 1 & 1 & 2 & 2 & 2 & \\
\hline 0 & 1 & 2 & 2 & 1 & 1 & 2 & 2 & 1 & 1 & 2 & 2 & 1 & 1 & 2 & 2 & 1 & 1 & 2 & 2 & 1 & 1 & 2 & 2 & 1 & 1 & 2 & 2 & 1 & 1 & 2 & \\
\hline 70 & 1 & 2 & 2 & 1 & 1 & 2 & 2 & 1 & 1 & 2 & 2 & 1 & 1 & 2 & 2 & 2 & 2 & 1 & 1 & 2 & 2 & 1 & 1 & 2 & 2 & 1 & 1 & 2 & 2 & 1 & \\
\hline 11 & 1 & 2 & 2 & 1 & 1 & 2 & 2 & 2 & 2 & 1 & 1 & 2 & 2 & 1 & 1 & 1 & 1 & 2 & 2 & 1 & 1 & 2 & 2 & 2 & 2 & 1 & 1 & 2 & 2 & 1 & \\
\hline 17 & 1 & 2 & 2 & 1 & 1 & 2 & 2 & 2 & 2 & 1 & 1 & 2 & 2 & 1 & 1 & 2 & 2 & 1 & 1 & 2 & 2 & 1 & 1 & 1 & 1 & 2 & 2 & 1 & 1 & 2 & \\
\hline 13 & 1 & 2 & 2 & 2 & 2 & 1 & 1 & 1 & 1 & 2 & 2 & 2 & 2 & 1 & 1 & 1 & 1 & 2 & 2 & 2 & 2 & 1 & 1 & 1 & 1 & 2 & 2 & 2 & 2 & 1 & \\
\hline 14 & 1 & 2 & 2 & 2 & 2 & 1 & 1 & 1 & 1 & 2 & 2 & 2 & 2 & 1 & 1 & 2 & 2 & 1 & 1 & 1 & 1 & 2 & 2 & 2 & 2 & 1 & 1 & 1 & 1 & 2 & \\
\hline J & 1 & 2 & 2 & 2 & 2 & 1 & 1 & 2 & 2 & 1 & 1 & 1 & 1 & 2 & 2 & 1 & 1 & 2 & 2 & 2 & 2 & 1 & 1 & 2 & 2 & 1 & 1 & 2 & 2 & 1 & \\
\hline 16 & 1 & 2 & 2 & 2 & 2 & 1 & 1 & 2 & 2 & 1 & 1 & 1 & 1 & 2 & 2 & 2 & 2 & 1 & 1 & 1 & 1 & 2 & 2 & 1 & 1 & 2 & 2 & 1 & 1 & 2 & \\
\hline 17 & 2 & 1 & 2 & 1 & 2 & 1 & 2 & 1 & 2 & 1 & 2 & 1 & 2 & 1 & 2 & 1 & 2 & 1 & 2 & 1 & 2 & 1 & 2 & 1 & 2 & 1 & 2 & 1 & 2 & 1 & \\
\hline 18 & 2 & 1 & 2 & 1 & 2 & 1 & 2 & 1 & 2 & 1 & 2 & 1 & 2 & 1 & 2 & 2 & 1 & 2 & 1 & 2 & 1 & 2 & 1 & 2 & 1 & 2 & 1 & 2 & 1 & 2 & \\
\hline 10 & 2 & 1 & 2 & 1 & 2 & 1 & 2 & 2 & 1 & 2 & 1 & 2 & 1 & 2 & 1 & 1 & 2 & 1 & 2 & 1 & 2 & 1 & 2 & 2 & 1 & 2 & 1 & 2 & 1 & 2 & \\
\hline 20 & 2 & 1 & 2 & 1 & 2 & 1 & 2 & 2 & 1 & 2 & 1 & 2 & 1 & 2 & 1 & 2 & 1 & 2 & 1 & 2 & 1 & 2 & 1 & 1 & 2 & 1 & 2 & 1 & 2 & 1 & \\
\hline 21 & 2 & 1 & 2 & 2 & 1 & 2 & 1 & 1 & 2 & 1 & 2 & 2 & 1 & 2 & 1 & 1 & 2 & 1 & 2 & 2 & 1 & 2 & 1 & 1 & 2 & 1 & 2 & 2 & 1 & 2 & \\
\hline $2 L$ & 2 & 1 & 2 & 2 & 1 & 2 & 1 & 1 & 2 & 1 & 2 & 2 & 1 & 2 & 1 & 2 & 1 & 2 & 1 & 1 & 2 & 1 & 2 & 2 & 1 & 2 & 1 & 1 & 2 & 1 & \\
\hline 23 & 2 & 1 & 2 & 2 & 1 & 2 & 1 & 2 & 1 & 2 & 1 & 1 & 2 & 1 & 2 & 1 & 2 & 1 & 2 & 2 & 1 & 2 & 1 & 2 & 1 & 2 & 1 & 1 & 2 & 1 & \\
\hline 24 & 2 & 1 & 2 & 2 & 1 & 2 & 1 & 2 & 1 & 2 & 1 & 1 & 2 & 1 & 2 & 2 & 1 & 2 & 1 & 1 & 2 & 1 & 2 & 1 & 2 & 1 & 2 & 2 & 1 & 2 & \\
\hline 25 & 2 & 2 & 1 & 1 & 2 & 2 & 1 & 1 & 2 & 2 & 1 & 1 & 2 & 2 & 1 & 1 & 2 & 2 & 1 & 1 & 2 & 2 & 1 & 1 & 2 & 2 & 1 & 1 & 2 & 2 & \\
\hline 26 & 2 & 2 & 1 & 1 & 2 & 2 & 1 & 1 & 2 & 2 & 1 & 1 & 2 & 2 & 1 & 2 & 1 & 1 & 2 & 2 & 1 & 1 & 2 & 2 & 1 & 1 & 2 & 2 & 1 & 1 & \\
\hline 27 & 2 & 2 & 1 & 1 & 2 & 2 & 1 & 2 & 1 & 1 & 2 & 2 & 1 & 1 & 2 & 1 & 2 & 2 & 1 & 1 & 2 & 2 & 1 & 2 & 1 & 1 & 2 & 2 & 1 & 1 & \\
\hline 28 & 2 & 2 & 1 & 1 & 2 & 2 & 1 & 2 & 1 & 1 & 2 & 2 & 1 & 1 & 2 & 2 & 1 & 1 & 2 & 2 & 1 & 1 & 2 & 1 & 2 & 2 & 1 & 1 & 2 & 2 & \\
\hline 29 & 2 & 2 & 1 & 2 & 1 & 1 & 2 & 1 & 2 & 2 & 1 & 2 & 1 & 1 & 2 & 1 & 2 & 2 & 1 & 2 & 1 & 1 & 2 & 1 & 2 & 2 & 1 & 2 & 1 & 1 & \\
\hline 30 & 2 & 2 & 1 & 2 & 1 & 1 & 2 & 1 & 2 & 2 & 1 & 2 & 1 & 1 & 2 & 2 & 1 & 1 & 2 & 1 & 2 & 2 & 1 & 2 & 1 & 1 & 2 & 1 & 2 & 2 & \\
\hline 31 & 2 & 2 & 1 & 2 & 1 & 1 & 2 & 2 & 1 & 1 & 2 & 1 & 2 & 2 & 1 & 1 & 2 & 2 & 1 & 2 & 1 & 1 & 2 & 2 & 1 & 1 & 2 & 1 & 2 & 2 & \\
\hline 32 & 2 & 2 & 1 & 2 & 1 & 1 & 2 & 2 & 1 & 1 & 2 & 1 & 2 & 2 & 1 & 2 & 1 & 1 & 2 & 1 & 2 & 2 & 1 & 1 & 2 & 2 & 1 & 2 & 1 & 1 & \\
\hline
\end{tabular}

\section{Validation of the measurement scale}

The accuracy of the scale was justified by measuring the MDs of the known abnormal observations. The data from abnormal observations were normalized using mean and standard deviation obtained from the normal observations. The MDs were obtained from the abnormal observations using the correlation matrix of normal observations in Equation 1. After calculating MDs, the average MD for the normal observations was compared with that for abnormal observations. The higher values of MDs for the abnormal group validate the accuracy of the measurement scale.

Table 3 Average response for the larger-the-better $\mathrm{S} / \mathrm{N}$ ratio (human resource)

\begin{tabular}{lcccccccccc}
\hline & $\boldsymbol{h}_{\mathbf{1}}$ & $\boldsymbol{h}_{\mathbf{2}}$ & $\boldsymbol{h}_{\mathbf{3}}$ & $\boldsymbol{h}_{\mathbf{4}}$ & $\boldsymbol{h}_{\mathbf{5}}$ & $\boldsymbol{h}_{\mathbf{6}}$ & $\boldsymbol{h}_{\mathbf{7}}$ & $\boldsymbol{h}_{\mathbf{8}}$ & $\boldsymbol{h}_{\mathbf{9}}$ & $\boldsymbol{h}_{\mathbf{1 0}}$ \\
\hline Level 1 & -31.57 & -33.31 & -31.29 & -29.38 & -28.41 & -29.82 & -28.39 & -28.46 & -26.79 & -27.64 \\
Level 2 & -29.19 & -27.46 & -29.47 & -31.38 & -32.35 & -30.94 & -32.37 & -32.30 & -33.97 & -33.12 \\
Gain & -2.38 & -5.85 & -1.82 & 2.00 & 3.94 & 1.12 & 3.99 & 3.84 & 7.18 & 5.48 \\
\hline
\end{tabular}


Table 4 Average response for the larger-the-better $\mathrm{S} / \mathrm{N}$ ratio (equipment)

\begin{tabular}{lcccc}
\hline & $\boldsymbol{q}_{\mathbf{1}}$ & $\boldsymbol{q}_{\mathbf{2}}$ & $\boldsymbol{q}_{\mathbf{3}}$ & $\boldsymbol{q}_{\mathbf{4}}$ \\
\hline Level 1 & -28.38 & -31.01 & -28.39 & -30.86 \\
Level 2 & -32.39 & -29.76 & -32.37 & -29.90 \\
Gain & 4.01 & -1.25 & 3.98 & -0.96 \\
\hline
\end{tabular}

Based on the MTS theory, the MD of abnormal observations will be larger than the MD of normal observations if this is a good scale. Otherwise, one has to resample or find new subcriteria (if applicable) to build the MS again.

\section{Identification of the prime set of subcriteria}

At this stage, the prime set of subcriteria was identified by applying orthogonal arrays (OAs) and signal-to-noise $(\mathrm{S} / \mathrm{N})$ ratios. The orthogonal arrays are used so that the interactions between control factors are almost evenly distributed to other columns of the orthogonal arrays and confounded to various main effects (Taguchi et al. 2005). Then, the appropriate OA was selected depending on the total degrees of freedom required to study the individual subcriteria. The number of degrees of freedom is one less than the number of levels associated with the subcriterion (Antony and Antony 2001). The individual ' $k$ ' subcriteria under study were assigned to the first $k$ columns of the identified OA (Taguchi 1987). Level 1 in the identified OA column represents the presence of a subcriterion, and level 2 represents the absence of that subcriterion. Inside an $\mathrm{OA}$, each row represents the experimental combination of a run (Table 2).

Using the subcriteria combinations in the identified OA, MDs for the known abnormal observations were obtained using Equation 1. From the MDs, the largerthe-better $\mathrm{S} / \mathrm{N}$ ratio was obtained for the qth run using the formula (Taguchi et al. 2001)

$$
\begin{aligned}
\frac{S}{N} \text { ratio } & =-10 \log _{10}\left[\left(\frac{1}{t}\right) \sum_{i=1}^{t} \frac{1}{\mathrm{MD}_{i}^{2}}\right] \quad j \\
& =1,2, \ldots, t
\end{aligned}
$$

where $t$ is the number of subcriteria presented for a given combination of the experimental run.

An average $\mathrm{S} / \mathrm{N}$ ratio was calculated for each subcriterion at levels 1 and 2 . Subsequently, gain in $\mathrm{S} / \mathrm{N}$ ratio values was calculated as

Table 5 Average response for the larger-the-better $\mathbf{S} / \mathrm{N}$ ratio (market)

\begin{tabular}{lccccc}
\hline & $\boldsymbol{m}_{\mathbf{1}}$ & $\boldsymbol{m}_{\mathbf{2}}$ & $\boldsymbol{m}_{\mathbf{3}}$ & $\boldsymbol{m}_{\mathbf{4}}$ & $\boldsymbol{m}_{\mathbf{5}}$ \\
\hline Level 1 & -29.78 & -27.13 & -26.69 & -26.60 & -28.02 \\
Level 2 & -30.99 & -33.64 & -34.07 & -34.17 & -32.74 \\
Gain & 1.21 & 6.51 & 7.38 & 7.57 & 4.72 \\
\hline
\end{tabular}

Table 6 Average response for the larger-the-better S/N ratio (supply chain)

\begin{tabular}{lcccc}
\hline & $\boldsymbol{c}_{\mathbf{1}}$ & $\boldsymbol{c}_{\mathbf{2}}$ & $\boldsymbol{c}_{\mathbf{3}}$ & $\boldsymbol{c}_{\mathbf{4}}$ \\
\hline Level 1 & -29.55 & -29.29 & -29.68 & -30.16 \\
Level 2 & -31.22 & -31.47 & -31.08 & -30.60 \\
Gain & 1.67 & 2.18 & 1.40 & 0.44 \\
\hline
\end{tabular}

$$
\text { Gain }=\left(\text { average of } \frac{S}{N} \text { ratio }\right)_{\text {level } 1}-\left(\text { average of } \frac{S}{N} \text { ratio }\right)_{\text {level } 2} .
$$

If the gain is positive, we keep the subcriterion; if not, then we exclude it for the next step.

\section{Confirmation run}

A confirmation run was performed with the prime set of subcriteria identified from the step before. The reduced measurement scale was constructed by utilizing the prime set of subcriteria identified, and then MDs corresponding to the abnormal observations were obtained using Equation 1. In the next step, the average MD based on the abnormal observations obtained with the prime set of subcriteria identified was compared to that gained from all the subcriteria originally used. If the average MD of abnormal group with the prime set of subcriteria identified was lower than that of all the subcriteria, then retain the excluded subcriteria also in the prime set of subcriteria identified; if not, then consider only the subcriteria which were identified as the prime set from the previous step, for the anticipation of further observations.

\section{Results and discussion}

The Mahmoudabad Training Center is an educational center for training personnel of petroleum industries (about 100,000 persons) and also staffs from other organizations needing special on-the-job and recruitment trainings. The center utilizes different educational organizations as supplier. We conducted the proposed method with the aid of 29 normal observations; the MDs corresponding to all these observations were calculated. Mahalanobis space was defined for all main criteria with the help of the MDs obtained for 29 observations. The

Table 7 Average response for the larger-the-better $\mathrm{S} / \mathrm{N}$ ratio (rules)

\begin{tabular}{lcccc}
\hline & $\boldsymbol{r}_{\mathbf{1}}$ & $\boldsymbol{r}_{\mathbf{2}}$ & $\boldsymbol{r}_{\mathbf{3}}$ & $\boldsymbol{r}_{\mathbf{4}}$ \\
\hline Level & -31.80 & -31.28 & -26.10 & -29.03 \\
Level2 & -28.96 & -29.49 & -34.66 & -31.74 \\
Gain & -2.84 & -1.79 & 8.56 & -2.71 \\
\hline
\end{tabular}


data from the 9 abnormal observations were normalized utilizing mean and standard deviation gained from the 29 normal observations. The MDs corresponding to all these observations were estimated for the main criteria. Since the average MD of the abnormal group with the prime set of subcriteria identified was lower than that of all the subcriteria, it would be valid.

There are many orthogonal arrays in Taguchi's method (David 2001). Commonly, for surveying of significant subcriteria from the main criteria, the orthogonal arrays of $L_{12}\left(2^{11}\right), L_{s}\left(2^{7}\right)$, and $L_{4}\left(2^{3}\right)$ are used for the individual main criterion appropriately. The important set of subcriteria will be assigned to each main criterion accordingly. The weakness of such a method is that we only compare subcriteria which belong to one type of main criterion isolately. However, in this method, the $L_{32}\left(2^{27}\right)$ orthogonal array was utilized for the identification of the prime set of subcriteria with minimum number of subcriteria combinations. Hereby, we have considered the interactions among all criteria as whole. The strength of such a method is considering the whole combinations of subfactors from the main criteria concurrently.

In Tables 3, 4, 5, 6, and 7, ' 1 ' (or level 1) represents inclusion of the subcriterion and ' 2 ' (or level 2) the exclusion of the subcriterion. An average $\mathrm{S} / \mathrm{N}$ ratio was obtained for each subcriterion at levels 1 and 2. Subsequently, gain in $\mathrm{S} / \mathrm{N}$ ratio was calculated by the difference between the average $\mathrm{S} / \mathrm{N}$ ratio value at level 1 and level 2 (Tables 3, 4, 5, 6, and 7).

From Table 3, it is clear that in the main criteria human resource, the seven subcriteria such as $h_{4}, h_{5}$, $h_{6}, h_{7}, h_{8}, h_{9}$, and $h_{10}$ have positive gains. That means these subcriteria have higher average responses when they are part of the system (level 1). Hence, these subcriteria were considered to be useful for the confirmation run. A similar interpretation was true for the rest of the main criteria in Tables 4 and 7.

The obtained results from Tables 3, 4, 5, 6, and 7 show the subcriteria which are significant and more effective in formulating strategy as mentioned in Table 1. Based on the samples taken, it can be stated that the subcriteria relating to human resource, supply chain, and market as main criteria have more influences and should be considered more closely in strategy formulation.

\section{Conclusion}

A simple-to-use MTS-based decision tool that assists in the selection of significant criteria which will be useful for the identification of suitable educational institutions has been developed. One can use the MTS-based tool in the education system without much knowledge of statistics. If the discrimination is performed alone by an individual criterion, it may produce a misleading result. The proposed MTS decision tool combines all criteria into an MD index with consideration of the correlation among all criteria. The advantage of this method compared to other methods such as SWOT is that it considers not only the whole factors in environmental scanning but also the interaction among factors by using orthogonal array analysis. The proposed decision tool can be easily adapted to other closely related industries such as tourism, agriculture, and environmental engineering.

\section{Competing interests}

The authors declare that they have no competing interests.

\section{Authors' contributions}

SAH, NS, and IM carried out environmental scanning, explored and labeled factors, designed the case study, and prepared the manuscript. HA and HS participated in the case study and performed the statistical analysis. All authors read and approved the final manuscript.

\section{Acknowledgments}

The authors wish to express their appreciation to the National Iranian Oil Company (NIOC) for sponsorship, data preparation, and cooperation. Also, we would like strongly to appreciate the valuable comments received from four referees through this research process.

\section{Author details}

${ }^{1}$ National Iranian Oil Company - Mahmoudabad Training Center, Mahmoudabad, Iran. ${ }^{2}$ Department of Industrial Engineering, Mazandaran University of Science and Technology, Babol, Iran. ${ }^{3}$ School of Industrial Engineering, College of Engineering, University of Tehran, Tehran, Iran.

Received: 3 April 2012 Accepted: 9 September 2013

Published: 16 September 2013

\section{References}

Antony J, Antony FJ (2001) Teaching the Taguchi method to industrial engineers. Work Study 50:141-149

Bellman RE, Zadeh LA (1970) Decision-making in a fuzzy environment. Manag Sci 17(4):141-164

Bunn D, Thomas H (1977) Decision analysis and strategic policy formulation. Long Range Plann 10(6):23-30

Chen SH, Hsieh CH (2000) Representation, ranking, distance, and similarity of L-R type fuzzy number and application. Aust J Intell Inform Process Syst 6(4):217-229

Chen SJ, Huang CL, Huang FP (1992) Fuzzy multiple attribute decision making methods and applications. Springer, Berlin

David FR (2001) Strategic management, concepts and cases, 8th edn. Prentice Hall, New Jersey

Dincer O (2004) Strategy management and organization policy. Beta Publication, Istanbul

Dyson RG (2004) Strategic development and SWOT analysis at the University of Warwick. Eur J Oper Res 152(1):631-640

Gordon JRM, Lee PM, Lucas HC (2005) A resource-based view of competitive advantage at the Port of Singapore. J Strateg Inf Syst 14(1):69-86

Hadighi SA, Mahdavi I, Sahebjamnia N, Mahdavi-Amiri N (2012) A new approach in strategy formulation using clustering algorithm: an instance in a service company. Int J Ind Eng 23(2):125-142

Hadighi SA, Sahebjamnia N, Mahdavi I, Shirazi MA (2013) A framework for strategy formulation based on clustering approach: a case study in a corporate Organization. Knowl-Based Syst 49:37-49

Hill T, Westbrook R (1997) SWOT analysis: it's time for a product recall. Long Range Plann 30(1):46-52

Killen CP, Walker M, Hunt RA (2005) Strategic planning using QFD. Int J Qual Reliab Manag 22(1):17-29

Kuo-liang L, Shu-chen L (2008) A fuzzy quantified SWOT procedure for environmental evaluation of an international distribution center. Inf Sci 178:531-549

Paiva EL, Roth AV, Fensterseifer JE (2008) Organizational knowledge and the manufacturing strategy process: a resource-based view analysis. J Oper Manag 26(1):115-132 
Russell RS, Taylor BW III (2006) Operations management. Wiley, New York, pp 200-211

Taguchi G (1987) System of experimental design. Dearborn, Michigan, and White Plain. ASI Press and UNIPUB-Kraus International Publications, New York

Taguchi G, Jugulum R (2000) New trends in multivariate diagnosis. Indian J Stat 62(1):233-248

Taguchi G, Jugulum R (2002) The Mahalanobis-Taguchi Strategy. Wiley, New York Taguchi G, Chowdhury S, Wu Y (2001) The Mahalanobis-Taguchi System. McGraw-Hill, New York

Taguchi G, Chowdhury S, Wu Y (2005) Taguchi's quality engineering handbook. Wiley, New York, p 595

doi:10.1186/2251-712X-9-26

Cite this article as: Hadighi et al:: Mahalanobis-Taguchi System-based criteria selection for strategy formulation: a case in a training institution. Journal of Industrial Engineering International 2013 9:26.

\section{Submit your manuscript to a SpringerOpen ${ }^{\circ}$} journal and benefit from:

- Convenient online submission

$\checkmark$ Rigorous peer review

- Immediate publication on acceptance

- Open access: articles freely available online

- High visibility within the field

- Retaining the copyright to your article 